\title{
Ambulatory endoscopy - Perspectives from the community
}

\author{
Iain Murray MD¹, Naoki Chiba MD MSc FRCPC², Paul Adams MD³ (Editor-in-Chief)
}

$\mathrm{T}$ his is the initial article in a series of ongoing interviews with gastroenterologists and affiliated specialties. The concept is to provide up-to-date perspectives on emerging topics that will affect gastroenterologists in Canada. The topic of opening an independent endoscopy facility is of great interest, and in this interview, I speak to two gastroenterologists who have their own facilities (Figure 1).

Dr Iain Murray (IM) is a practicing gastroenterologist in Markham, Ontario. He opened the Intestinal Health Institute in 2003 and his practice is restricted to this ambulatory endoscopy centre. Dr Naoki Chiba (NC) is a practicing gastroenterologist in Guelph, Ontario. He opened an outpatient endoscopy centre in 1992, maintains active privileges at the Guelph General Hospital and is Associate Clinical Professor of Medicine at McMaster University, Hamilton, Ontario.

PA: Can you tell what led up to the opening of your ambulatory endoscopy centre?

IM: Patients wait long enough to see a gastroenterologist. With limited endoscopy access at the hospital the wait for a procedure was longer than the wait for consultation. The amount of endoscopy I can do no longer limits my practice. We are not dependent on hospital budget for providing access for the community.

The main advantage is being able to control who gets a procedure, and when. One of my greatest sources of frustration at the hospital was being unable to do urgent cases. To get permission to perform an urgent case I used to have to ask the endoscopy nurse, the recovery room nurse and, on one occasion, a procedure was cancelled because the endoscopy technicians had cleaned too many scopes that day. We can do as many procedures as we wish during the day, without having to rely on hospital funding. Added to that was the frustration of internal medicine call. I used to spend over an hour each day taking care of patients that should have been seen by a hospitalist. That hour is now spent doing what I am trained to do. NC: When I first started my practice, it was tough to get a job anywhere. As my family was from St Catharines and my wife's family was in Stoney Creek, we didn't want to move too far away. I knew there was a clinical need for a gastroenterologist in Guelph but the hospitals weren't quite ready to grant privileges right away. I had privileges in Fergus at Groves Memorial Hospital and I knew that I needed more endoscopy time to serve the community of Guelph so I basically gambled and set up my own endoscopy suite in the office.

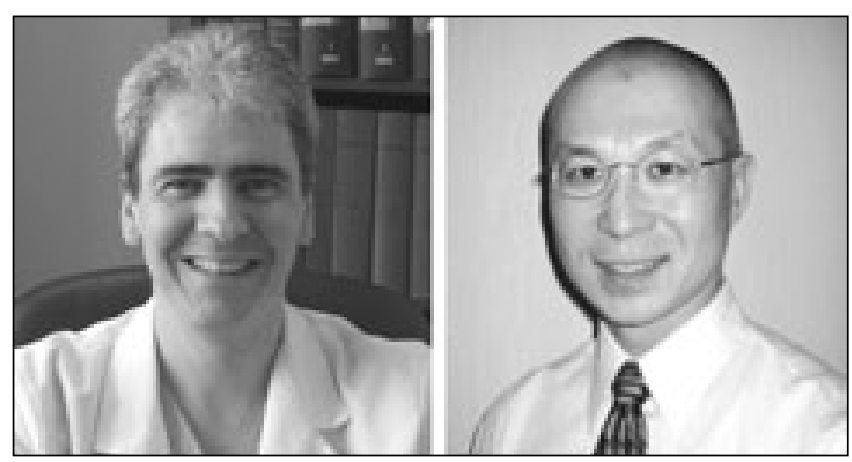

Figure 1) Dr Iain Murray, Markham, Ontario (left); Dr Naoki Chiba, Guelph, Ontario (right)

PA: Can you describe your centre?

IM: Our clinic is designed to have two endoscopy rooms, however, we find that one is all we need for two physicians. One physician does consultations on the day the other does procedures. Our recovery room holds four beds comfortably (Figure 2A). If we were to open the second room we would be limited by recovery room space.

We have five colonoscopes and two gastroscopes. They are cleaned by a technician using a Steris processor, which also sterilizes our reusable endoscopy equipment. We have one technician, three part-time nurses, and a medical secretary. We do our own dictations by voice recognition software, so we fax out consultations and procedure reports that day.

NC: We have one big room in the office separated by a pull curtain. One side has the endoscopy set-up with a fixed monitor screen and the scope equipment is on a cart (Figure 2B). The patient is scoped on this side and the stretcher turned around [depending on] whether the procedure is a gastroscopy or a colonoscopy. The patient is monitored with an oxygen saturation monitor and we have a crash cart in the room with oxygen, drugs and all resuscitation equipment. When the procedure $(s)$ is complete, the stretcher is turned into the other side of the room where they recover if they have had sedation. We pull the curtain closed and a family member sits with them and helps to keep an eye on the patient. If there's no sedation used, then the patient just gets dressed and goes home right away. In the same room we have the scope disinfectant in a fume hood. While the patient is recovering, the nurse cleans the scope and is literally about five feet away from the patient, ready to intervene if there is a problem. Once the scope is

${ }^{1}$ Intestinal Health Institute, Markham; ${ }^{2}$ Surrey GI Clinic/Research, Guelph; and McMaster University, Hamilton; ${ }^{3}$ London Health Sciences Centre, London, Ontario

Correspondence: Drs Murray and Chiba are available for further discussion on this topic by e-mail at gimurray@bellnet.ca and chiban@on.aibn.com

Received for publication May 6, 2005. Accepted May 12, 2005 

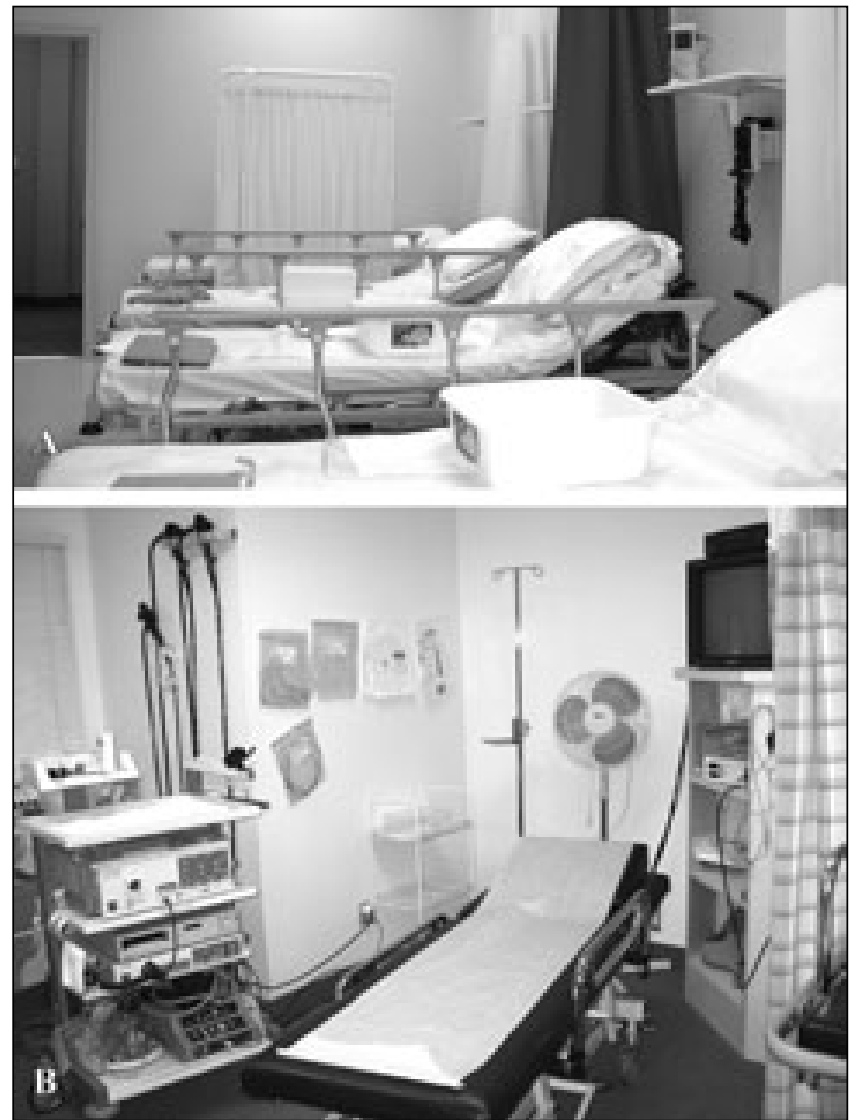

Figure 2) A Ambulatory endoscopy facility of Dr Murray in Markham, Ontario; B Ambulatory endoscopy facility of Dr Chiba in Guelph, Ontario

soaking, the nurse checks in the next patient and we go ahead with the next scope. The recovering patient usually is still there while we do the next procedure. We scope with one nurse and this works well as our volume is low. I use an older Olympus processor and have two video colonoscopes and two fibre optic gastroscopes. I also have a video attachment for the gastroscope if needed to capture still photographs. I have a partner who also scopes but we never scope at the same time. PA: Can you give us an idea of a typical daily schedule?

IM: We do about 11 procedures a day. These could be gastroscopy, colonoscopy or combination. During a working day our sterilizer can handle about 14 scopes a day.

NC: We usually scope three mornings a week and we do somewhere between four and six procedures on average. This is a mix of, say, two gastroscopies and four colonoscopies. Sometimes we'll do a flexible sigmoidoscopy instead of a colonoscopy. We often use no sedation in the office.

PA: Do the patients have any additional non-OHIP charges?

IM: Naturally, we cannot charge patients an additional fee. We do request an administrative fee to handle any uninsured services.

NC: No.

PA: The Independent Health Care Facilities Act was previously considered an impediment to the development of outpatient endoscopy. Can you comment? Is ambulatory endoscopy illegal in Ontario or is charging an extra fee illegal?

IM: This is not an independent health care facility. This is an office, where gastroscopies and colonoscopies are performed. For years, flexible sigmoidoscopies have been performed in offices, and dentists regularly give sedation to patients in an out of hospital setting. There are many clinics, similar to ours, that have been up and running for some time.

NC: Certainly scoping in my private office is generally expensive because we get no additional fees as we would if we were considered an independent health care facility. However, we have had our equipment a long time, we take care of it, it is older so less expensive and the cost is not that prohibitive. However, if we started new now, equipment is so expensive that we would have to have much greater volume of cases to make it financially worthwhile. I don't think ambulatory endoscopy is illegal and I was never sure about charging an extra fee so I have never charged one. I do also scope a lot at the Groves Memorial Hospital and the Guelph General Hospital so patients always have an alternative. In the office, if the patient thinks they will need sedation I give them a prescription for meperidine and midazolam and they bring it to the office. Most private drug plans will cover the sedation, and for those patients that prefer less hassle than from going to the hospital, they are willing to pay for the prescriptions.

PA: Do you select only low-risk patients? How is that defined? IM: We do not accept consultations from nursing homes, largely because of the difficulty in transporting patients. Other than that we rely on family doctors to have common sense in their referral pattern. We do not triage consultations based on patient age or frailty. Very rarely, I have asked a hospital-based colleague to see somebody that would not be appropriate to undergo a procedure in an out-of-hospital setting.

NC: Since I also scope at the hospital I do select healthy patients to scope in the office. These are usually those with stable disease, even those with coronary artery disease. I tend to select those that I think I can scope without much sedation (or no sedation) and I have become pretty good at selecting these patients over the years. I haven't had a serious problem in the 13 years I have been scoping here. I don't want a patient to lie around recovering for a long time if they have had a lot of sedation so these patients are directed to the hospital. Also, if a patient needs fentanyl or morphine I scope them at the hospital. PA: Have you altered your approach to sedation at your centre? Do you buy all of the medications or does the patient?

IM: I use the same sedation I used to use in the hospital setting. I find we are using less sedation, possibly because patients are more relaxed in this setting. The sedation (along with other medication, such as crash cart drugs) is purchased from a local drugstore. We cannot charge patients for medication.

NC: Generally, we select patients who will use little or no sedation to scope in the office. Most of the patients bring their own sedation, ie, they fill their own prescription but we have drug on hand. I usually use meperidine and midazolam.

PA: Are you hesitant to use disposable accessories? Probes, baskets, banding, etc.

IM: We use the same approach to disposable accessories as we used in the hospital. We dispose of snares, but use reusable biopsy forceps, which are sterilized between uses.

NC: We don't do complicated procedures in the office. We use reusable biopsy forceps and disposable snares. I don't do banding, any acute GI bleeds that may need injection or bipolar coagulation nor esophageal dilation but we do simple polypectomy. PA: Are there additional insurance requirements for an ambulatory endoscopy facility? 
IM: We have additional insurance to cover the cost of the endoscopes.

NC: I don't think so. I have always thought that this was a part of my professional qualifications as a gastroenterologist and hence covered by CMPA [Canadian Medical Protective Association].

PA: Why has this not expanded in Canada? Is it the initial capital cost? Is it the low profit margins? Do you see this expanding in the next 10 years in Canada?

IM: I estimate it cost a quarter of a million dollars to set up this facility, which can be seen as prohibitive. Also there is higher overhead as we now have to provide nurses and equipment. A balance is struck between professional satisfaction and remuneration. NC: I don't know for certain but I think it is because physicians are not willing to put out the initial financial outlay. Since it really doesn't cost them anything out-of-pocket to scope at the hospital, they don't feel obliged to pay any of their own costs. I think my colleagues will start doing this more as they tire of working at the hospital. There's no politics here. Scoping in the office has great freedom but I think that what I do, that is, scope in the office and at the hospital, is ideal. After all, the more demanding and costly procedures can be done at the hospital and I can do therapeutic ERCP [endoscopic retrograde cholangiopancreatography] there but not in the office.

PA: Do you see a facility fee coming for endoscopy centres in the future?

IM: There has been talk of a technical fee for these procedures in Ontario. There has been concerns that this would spark an exodus of gastroenterologists from the hospital setting. Certainly cardiologists and radiologists have technical fees, yet hospitals are still able to function. I would argue that endoscopy does not need to be performed in a hospital setting. The procedure can easily be performed in out-of-hospital centres, saving hospital resources for those who are in need of hospitalization. As these procedures can be performed safely and more efficiently in an out-of-hospital setting, why rely on hospitals, with their limited global budget, to provide access to endoscopy?

NC: I am hopeful that this will be the case. I think that once the government realizes that the demand for screening colonoscopy is becoming overwhelming, they may pay some fee. I expect that this will be less than at the hospital but this makes sense to me. That is, the government has a chance to save some money while accomplishing the same output. The costs are going up, especially with the increasing demands for using disposables. With that there should be a clear policy as to what the government will allow us to charge to the patient, or they need to come up with a facility fee to help us offset our costs. In essence, outpatient scope clinics end up doing the health care system a big favour as the costs would be lower for the government and the patient gets more timely care.

PA: How do you deal with complications that may occur at your ambulatory endoscopy centre?

IM: We refer the few and far between complications to the local surgeons. We have an alliance with local surgeons as we send many colon cancer cases to them, all worked up and ready for an operation. Postpolypectomy bleeds are treated in our clinic, unless they are hemodynamically unstable. Our local emergency department refers acute cases to us, which we see urgently, thereby helping out the hospital.

NC: I have not had any complications but if I did I would look after them myself in the hospital anyways.
PA: Is virtual colonoscopy a threat to the success of ambulatory endoscopy centres?

IM: I suspect virtual colonoscopy will generate more business. More people will be screened in the first place, and virtual colonoscopies generate colonoscopy $27 \%$ of time, either for true findings or false positives. In this case, the type of patient referred will be more likely to have pathology, the very people we should be seeing.

NC: Absolutely not. If virtual colonoscopy identifies more polyps, etc, our workload would change to have a higher load of therapeutic cases. In essence, I think it will increase my workload and frankly, as a therapeutic endoscopist, I think it will enhance my practice.

PA: Is a reduced waiting time the major attraction to your patients or do they also prefer the ambulatory settting?

IM: I am not convinced our waiting list is shorter than anywhere else. I AM convinced our patients prefer to have these procedures done in an out-of-hospital setting.

NC: My patients love this setting. Consider that the patient shows up just before the scope (compared to $2 \mathrm{~h}$ preprocedure at the hospital), they get scoped and go home shortly thereafter. It is unusual for a patient to be here more than $2 \mathrm{~h}$ total. This is very convenient for them. There is almost no stress here for them.

PA: Are there conflicts of interest when you are running your own endoscopy centre?

IM: I see patients in patient consultation and perform endoscopy as indicated. I am performing the procedure myself, and am not invoking a third-party, so I see no conflict.

NC: Since I also work out of two hospitals, I don't think there is any conflict of interest.

PA: Can you comment on the advantages and disadvantages of being in control of your own ambulatory endoscopy centre?

IM: As already mentioned, we have control over the waiting list for endoscopy after consultation, we do not need to rely on hospital global budgets, and do not have to deal with the hospital administration. Office endoscopy appears to be more efficient than hospital-based procedures. This is beneficial for both the physician and the patient. It is quite possible that the majority of endoscopies will be performed in out of hospital facilities in the future. It is important that these clinics be subjected to quality assurance analysis to sure that high-quality, safe care is provided.

NC: The biggest advantage is that I am in total control. If I want to add a case then the case is added. I just have to tell my nurse to make sure she knows and I don't have to make any special arrangements. I can scope someone on short notice and I can do all my study-related scopes without any hassle. The biggest disadvantage is that you end up scoping lower risk patients. For me, the higher risk or the more challenging patient that will need a complicated therapeutic procedure has to be done at the hospital. For example, I am not willing to spend a huge amount of money on a balloon dilator. I can only do ERCP at the hospital. I think I have the ideal situation as I can do procedures both here in my office and also at the hospital. Since I am a trained endoscopist, I also like working at the hospital where I can use my skill to treat a larger group of patients in the community. 


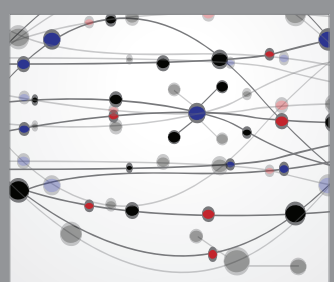

The Scientific World Journal
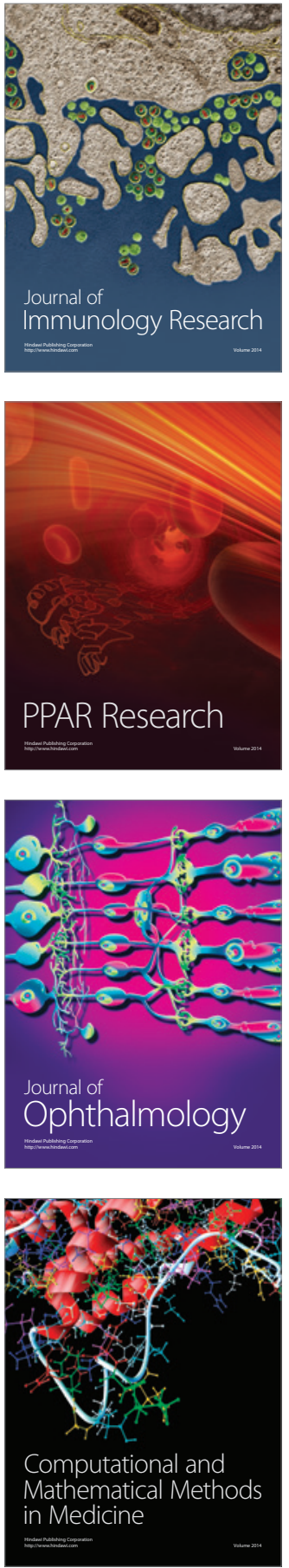

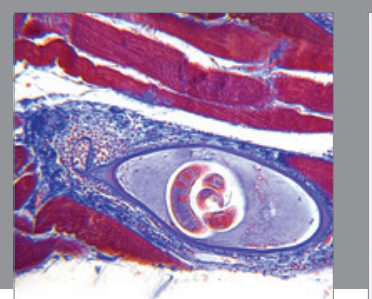

Gastroenterology Research and Practice

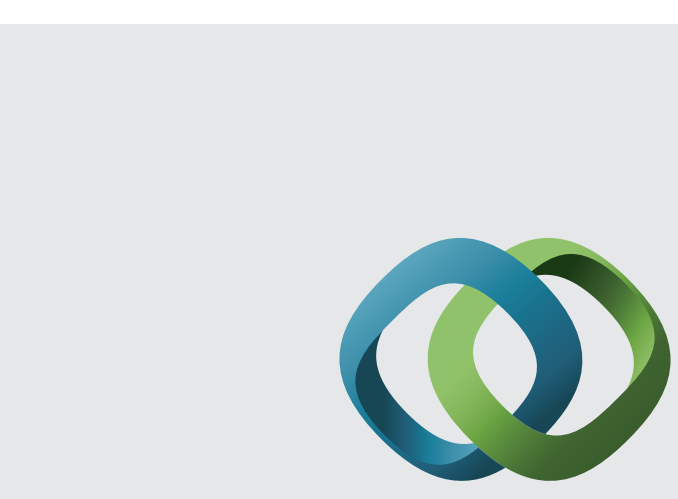

\section{Hindawi}

Submit your manuscripts at

http://www.hindawi.com
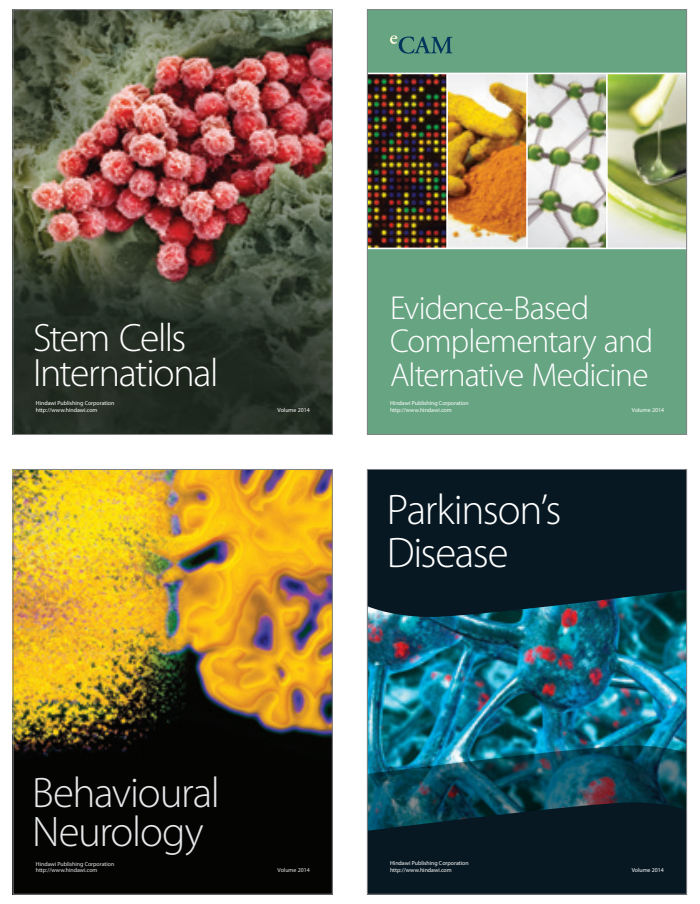
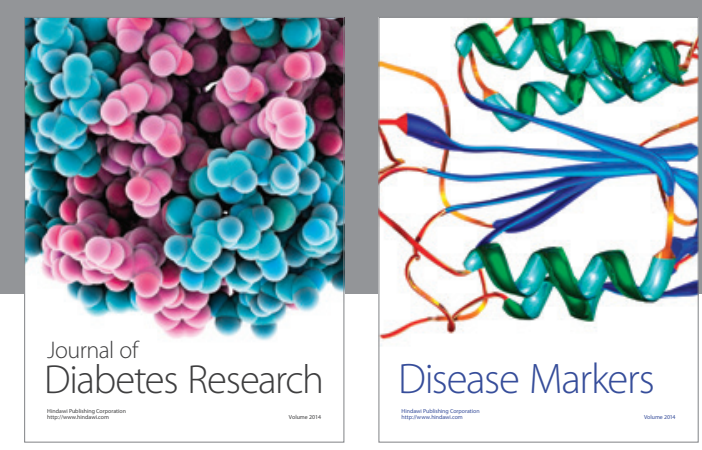

Disease Markers
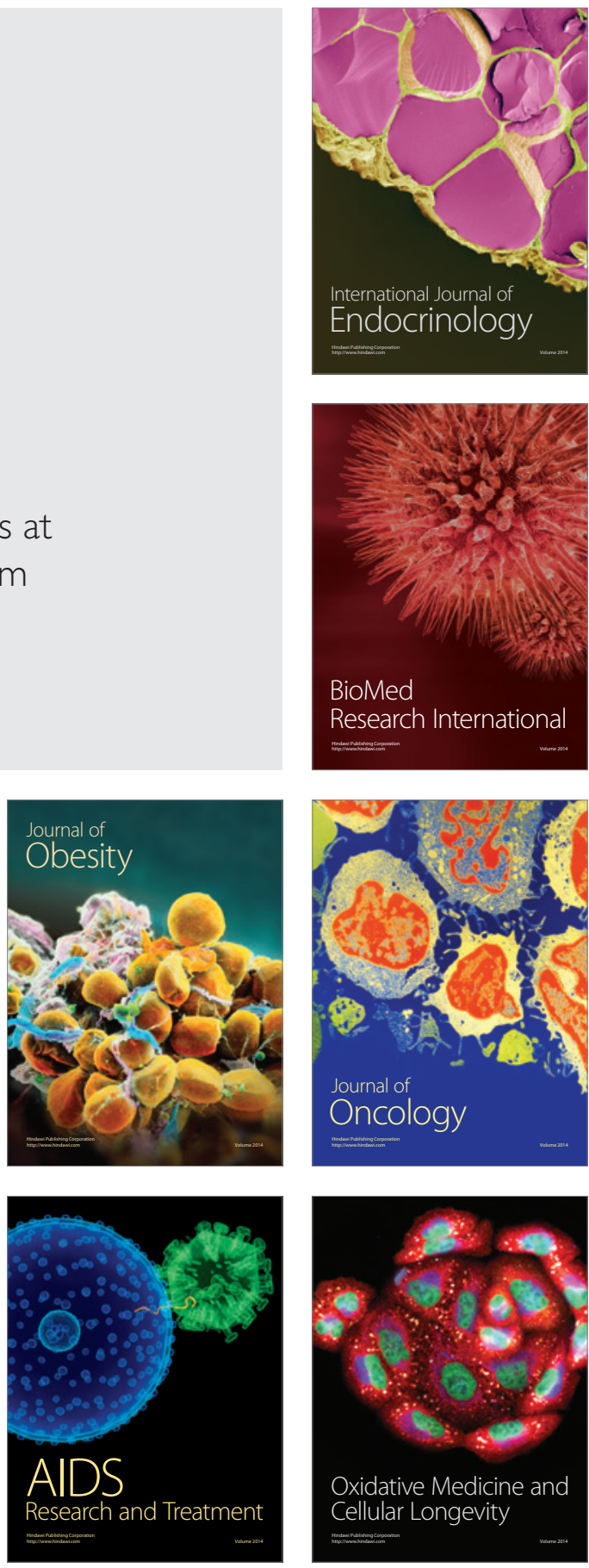